\title{
BIOATIVIDADE DE EXTRATOS VEGETAIS CONTRA PATÓGENOS DE SEMENTES DE AMENDOIM
}

\author{
Thiago Costa Ferreira1, Ana Lucia Araujo Cunha², Elida Barbosa Correa². \\ ${ }^{1}$ Universidade Estadual Julio de Mesquita Filho, R. Dr. José Barbosa de Barros, 1780 - Jardim Paraiso, Botucatu, SP, ${ }^{2}$ Universidade \\ Estadual da Paraiba - Campus II - Zona Rural - Lagoa Seca, PB. \\ *Autor para correspondência: ferreira_uepb@hotmail.com
}

RESUMO: A utilização de espécies vegetais como fungicidas naturais é uma promissora medida para o controle de patógenos veiculados às sementes. Sementes de amendoim têm elevada suscetibilidade ao ataque de fungos habitantes do solo. Devido à importância da cultura do amendoim, o objetivo do trabalho foi avaliar o efeito de extratos vegetais no controle de patógenos veiculados às sementes. Para tanto, foram utilizados extratos de alho (Allium sativum), carambola (Averrhoa carambola), eucalipto (Eucaliptus sp.), goiaba (Psidium guajava), mamona (Ricinus communis), melão-de-São-Caetano (Momordica charantia), mororó (Bauhinia cheilanta), mulungu (Erythrina mulungu), pinhão-manso (Jatropha curcas) e pitanga (Eugenia uniflora). Os extratos foram testados no tratamento de sementes e na avaliação do efeito fungitóxico sobre os patógenos Aspergillus flavus, Aspergillus niger e Penicillium sp. A aplicação dos extratos vegetais diminuiu a incidência fúngica nas sementes, sendo os extratos alcoólicos de goiaba, melão-de-São-Caetano e mamona, na concentração de 100\%, as mais efetivas. Os extratos vegetais alcoólicos testados mostraram efeito fungitóxico sobre os patógenos Aspergillus niger, Aspergillus flavus e Penicillium sp. Conclui-se que os extratos de goiaba, mamona e melão-de-São-Caetano são potenciais ferramentas para serem utilizadas no controle de patógenos veiculados às sementes.

Palavras-Chave: Aspergillus, Penicillium, Arachis hypogeae, Podridão de sementes.

\section{BIOACTIVITY OF PLANT EXTRATCS AGAINST PLANT PATHOGENS OF PEANUT SEEDS}

ABSTRACT: The use of plant species as natural fungicides is a promising measure for the control of seedborne pathogens. Peanut seeds have high susceptibility to attack by soil inhabiting fungi. Due to the importance of the peanut crop, the objective of this work was to evaluate the effect of plant extracts in the control of seedborne pathogens. For this purpose were tested tinctures of garlic (Allium sativum), carambola (Averrhoa carambola), eucalyptus (Eucalyptus sp.), guava (Psidium guajava), castor bean (Ricinus communis), bitter melon (Momordica charantia), mororó (Bauhinia cheilanta), coral tree (Erythrina mulungu), jatropha (Jatropha curcas), and brazilian cherry (Eugenia uniflora). The plant extracts were tested for seed treatment and in the evaluation of the antifungal effect on Aspergillus flavus, Aspergillus niger and Penicillium sp. pathogens. The application of plant extracts decreased the fungal incidence in seeds, being the alcoholic extracts of guava, bitter melon, and castor bean, in the concentration of $100 \%$, the most effective. Alcoholic plant extracts tested showed antifungal effect on the pathogens Aspergillus niger, Aspergillus flavus, and Penicillium sp. It was concluded that extracts of guava, bitter melon and castor bean are potential tools to be used to control seed borne pathogens.

KEY WORDS: Aspergillus, Penicillium, Arachis hypogeae, Seed rot.

\section{INTRODUÇÃO}

$\mathrm{O}$ amendoinzeiro (Arachis hypogeae L.) é uma Fabaceae com propriedades oleaginosas, sendo uma das culturas mais cultivadas no Brasil e no mundo (Silveira, 2010); no Nordeste brasileiro, é cultivado basicamente por agricultores familiares (Freitas et al., 2005; Santos et al., 2010). A produção estimada brasileira de grãos de amendoim para a safra 2013/2014 foi de aproximadamente 315,8 mil de toneladas, em uma área de 105,3 mil hectares com uma produtividade média de $2.998 \mathrm{~kg}_{\text {.ha-1 }}$ (Conab, 2014). 
Na cultura do amendoim pode-se encontrar várias doenças pós-colheita (Kimati et al, 2005), destacando-se as doenças causadas por fungos que vivem no solo e nas sementes, como por exemplo, Aspergillus spp., Penicilium spp. e Rhizopus spp. (Suassuna et al., 2008).

$\mathrm{Na}$ agricultura convencional, patógenos veiculados às sementes são controlados coma aplicação de fungicidas sintéticos. Porém, segundo Bettiol (2001) a eficácia desses fungicidas é questionável, pois a sua aplicação nos cultivos desequilibra o meio ambiente, mesmo quando utilizados em dosagens prescritas, por causa do seu efeito acumulativo. Devido aos danos causados pelo uso de agrotóxicos muitos autores têm recomendado o uso de tecnologias alternativas ao controle químico (Bruno et al., 2000; Fonseca e Botelho, 2010; Celoto et al., 2011; Medeiros et al., 2012).

Segundo Celoto et al. (2011), Medeiros et al. (2012) e Daronco (2013) a utilização de óleos e outros compostos vegetais, como extratos e extratos para 0 controle de patógenos veiculados as sementes tem alta eficiência, sendo a utilização desses compostos um método viável para a sanitização de sementes, de baixo custo e sustentável, quando comparado ao controle químico.

Devido à problemática gerada a partir do uso de agrotóxicos e a importância da cultura do amendoim, objetivou-se com esse trabalho avaliar 0 efeito de extratos vegetais no controle de patógenos veiculados às sementes de amendoim.

\section{MATERIAL E MÉTODOS}

As espécies utilizadas no trabalho (Tabela 1 , exceto 0 alho) foram coletadas no período entre janeiro a julho de 2014 no Campus II da Universidade Estadual da Paraíba, no Município de Lagoa Seca, Paraíba, sendo utilizadas folhas de plantas adultas. Os materiais coletados foram identificados e higienizados com água destilada em laboratório. Para o alho foram utilizados os bulbilhos, sendo esses adquiridos no comércio da cidade de Campina Grande, PB.

Tabela 1. Espécies vegetais utilizadas nos bioensaios.

\begin{tabular}{l|c|c}
\hline \multicolumn{1}{c|}{ Nome comum } & Nome científico & Família \\
\hline Alho & Allium sativum & Liliaceae \\
Carambola & Averrhoa carambola & Oxalidaceae \\
Eucalipto & Eucaliptus sp. & Myrtaceae \\
Goiaba & Psidium guajava & Myrtaceae \\
Mamona & Ricinus communis & Euforbiaceae \\
Melão-de-São-Caetano & Momordica charantia & Cucurbutaceae \\
Mororó & Bauhinia cheilantha & Casealpinaceae \\
Mulungu & Erythrina mulungu & Fabaceae \\
Pinhão-manso & Jatropha curcas & Euforbiacea \\
Pitanga & Eugenia uniflora & Myrtaceae \\
\hline
\end{tabular}

Os materiais coletados foram secos em estufa com circulação de ar a $40^{\circ} \mathrm{C}$, durante 48 horas, após secos foram triturados em moinho de facas, até a obtenção de um pó fino e posteriormente armazenado em recipientes de vidro e hermeticamente fechados até a preparação dos extratos vegetais.

Foram produzidos extratos alcoólicos (todas as espécies, Tabela 1) e aquosos (goiaba, mamona e melão-de-São-Caetano), de acordo com a seguinte metodologia: imersão dos pós-vegetais em solvente (álcool etílico a $70 \%$ para os extratos alcoólicos e água destilada para os extratos aquosos) e deixados em maceração por 48 horas, em temperatura ambiente, na ausência de luz. A quantidade de material vegetal utilizado correspondeu a $20 \%$ da relação peso/volume [peso do pó seco $(\mathrm{g})$ para volume do solvente $(\mathrm{mL})$ ]. Posteriormente, os extratos foram filtrados em papel filtro e armazenados em recipientes de vidro âmbar com capacidade para $0,5 \mathrm{~L}$ no escuro.

Três ensaios foram realizados para se avaliar a potencialidade dos extratos vegetais no controle de patógenos associados às sementes de amendoim var. BR1 (Embrapa Algodão). No primeiro ensaio foram utilizados extratos alcoólicos diluídos em água autoclavada a $20 \%$ das dez espécies vegetais descritas (Tabela 1); no segundo e terceiro ensaios foram utilizados os extratos na concentração de $100 \%$, alcoólicos ou aquosos, das espécies: goiaba, melãode-São-Caetano e mamona. A metodologia utilizada em ambos os ensaios foi a seguinte: sementes de amendoim foram imersas nos extratos, durante 15 minutos; além dos tratamentos com os extratos vegetais utilizou-se uma testemunha absoluta (imersão em água destilada autoclavada). 
Em ambos os experimentos, após a imersão nos extratos, as sementes foram colocadas para secar em temperatura ambiente por 30 minutos e acondicionadas em placas de Petri com o fundo coberto com discos de papel filtro autoclavado (15 cm de largura), utilizandose 25 sementes por placa de Petri, com quatro repetições. As placas foram acondicionadas em estufa tipo B.O.D., por três dias em temperatura constante de $21^{\circ} \mathrm{C}$, e por quatro dias a $25^{\circ} \mathrm{C}$, no escuro, para 0 primeiro experimento e, sete dias a $25^{\circ} \mathrm{C}$, no escuro, para o segundo e terceiro experimentos.

A fungitoxicidade dos extratos das espécies vegetais (Tabela 1) aos patógenos Aspergillus niger, Aspergillus flavus e Penicillium sp. isolados de sementes de amendoim var. BR1 foi testada por meio da adição de extratos alcoólicos na concentração de $20 \%$ ao meio BDA (Batata-Dextrose-Ágar). As espécies de Aspergillus foram identificadas pela sua morfologia, sendo os fungos cultivados em BDA. Para o tratamento testemunha, água destilada, na concentração de $20 \%$ foi adicionada ao meio de cultura BDA. Sobre o meio de cultura contido em placas de Petri foram depositados dez microlitros de suspensão fúngica de cada fungo, separadamente. As culturas foram incubadas em temperatura constante de $25 \pm 2^{\circ} \mathrm{C}$. $\mathrm{O}$ ensaio foi realizado de acordo com a metodologia adaptada de Venturoso et al. (2012). Para A. flavus a avaliação do crescimento micelial foi realizada no sétimo dia após a deposição da suspensão. $A$. niger e Penicillium sp. foram avaliados no quarto dia após o a adição da suspensão.
0 delineamento experimental utilizado foi 0 inteiramente casualizado, sendo avaliados para os ensaios in vivo: (i) percentagem de recobrimento fúngico, na qual foram avaliadas em microscópio estereoscópico as sementes de maneira individual inferindo a estes valores percentuais de recobrimento da superfície pelos fungos presentes nas sementes e (ii) incidência de fungos nas sementes, para o ensaio in vitro foi avaliado crescimento micelial dos fungos em meio de cultura BDA acrescido dos extratos vegetais, utilizando-se régua graduada.

Os resultados de porcentagem de recobrimento e incidência fúngica dos ensaios in vivo foram transformados através da fórmula arco seno $(x / 100)^{1 / 2}$ e analisados utilizando-se 0 teste de Tukey. Os resultados de crescimento micelial foram analisados utilizando-se o teste de Scott-Knott (para os experimentos in vitro). 0 programa estatístico Assistat 7.7 Beta foi utilizado para a realização das análises estatísticas (Silva e Azevedo, 2009).

\section{RESULTADOS E DISCUSSÃO}

Para o ensaio com 0 uso dos extratos alcoólicos a $20 \%$ de todas as espécies testadas (Tabela 1), as sementes de amendoim apresentaram predominância dos fungos: Aspergillus spp., Penicillium sp., Rhizopus sp. e Cladosporium sp. (Tabela 2). Dois morfotipos não identificados, com hifas não septadas e de coloração branca incidiram sobre $5 \%$ das sementes (dados não mostrados).

Tabela 2. Porcentagem de recobrimento micelial e incidência fúngica em sementes de amendoim BR1 após 0 tratamento ou não com extratos vegetais alcoólicas a $20 \%$.

\begin{tabular}{|c|c|c|c|c|c|}
\hline \multirow{3}{*}{$\mathrm{FV}^{1}$} & \multirow{3}{*}{$\begin{array}{c}\text { Porcentagem de } \\
\text { Recobrimento Micelial }\end{array}$} & \multicolumn{4}{|l|}{ VARIÁVEIS } \\
\hline & & \multicolumn{4}{|c|}{ ESPÉCIES FUNGICAS } \\
\hline & & Aspergillus spp. & Penicillium sp. & Rhizopus sp. & Cladosporium sp. \\
\hline QM (TRATAMENTO) & $0,12^{*}$ & $0,07^{* *}$ & $0,10^{*}$ & $0,44^{* *}$ & $0,07^{*}$ \\
\hline QM (RESÍDUO) & 0,05 & 0,02 & 0,04 & 0,08 & 0,03 \\
\hline CV $(\%)$ & 21,36 & 13,43 & 14,8 & 32,87 & 12,87 \\
\hline \multicolumn{6}{|c|}{ TRATAMENTOS $^{3}$} \\
\hline Testemunha & $0,53 a b$ & $0,91 \mathrm{~b}$ & $1,13 a$ & $1,31 \mathrm{a}$ & $1,34 \mathrm{a}$ \\
\hline Extrato de alho & $0,68 a b$ & $1,12 a b$ & $1,47 a$ & $0,89 a b c$ & $1,31 \mathrm{a}$ \\
\hline Extrato de carambola & $0,34 a b$ & $0,96 a b$ & $1,30 \mathrm{a}$ & $0,91 a b c$ & $1,48 \mathrm{a}$ \\
\hline Extrato de eucalipto & $0,60 \mathrm{ab}$ & $0,87 \mathrm{~b}$ & $1,20 \mathrm{a}$ & $1,34 \mathrm{a}$ & $1,22 \mathrm{a}$ \\
\hline Extrato de goiaba & $0,78 \mathrm{a}$ & $1,14 \mathrm{ab}$ & $1,19 a$ & $1,03 a b$ & $1,48 a$ \\
\hline Extrato de mamona & $0,20 \mathrm{~b}$ & $1,20 a b$ & $1,57 \mathrm{a}$ & $0,27 \mathrm{c}$ & $1,57 \mathrm{a}$ \\
\hline Extrato de melão-de-São-Caetano & $0,48 a b$ & $1,29 a$ & $1,32 \mathrm{a}$ & $0,45 \mathrm{bc}$ & $1,23 a$ \\
\hline Extrato de mororó & $0,31 \mathrm{ab}$ & $1,07 \mathrm{ab}$ & $1,49 a$ & $0,55 \mathrm{bc}$ & $1,39 a$ \\
\hline Extrato de mulungu & $0,37 a b$ & $0,95 a b$ & $1,57 \mathrm{a}$ & $0,97 a b c$ & $1,57 \mathrm{a}$ \\
\hline Extrato de pinhão-manso & $0,64 a b$ & $1,20 \mathrm{ab}$ & $1,57 \mathrm{a}$ & $0,84 a b c$ & $1,57 \mathrm{a}$ \\
\hline Extrato de pitanga & $0,55 \mathrm{ab}$ & $1,16 \mathrm{ab}$ & $1,32 \mathrm{a}$ & $1,02 \mathrm{ab}$ & $1,57 \mathrm{a}$ \\
\hline DMS & 0,55 & 0,35 & 0,7 & 0,7 & 0,45 \\
\hline
\end{tabular}

${ }^{1}$ Teste F [ ${ }^{*}$ Significativo a $1 \%$; ${ }^{* *}$ Significativo a $5 \%$; ns: Não Significativo];

${ }^{2}$ As médias foram transformadas através da fórmula: arco sen $(\sqrt{ } \mathrm{x} / 100)$;

${ }^{3}$ Tratamentos seguidos pelas mesmas letras não diferem entre si; 
A aplicação dos extratos vegetais a 20\% de concentração não diminuiu a porcentagem de recobrimento micelial dos fungos e a incidência de Aspergillus spp., Penicillium sp. e Cladosporium sp. nas sementes (Tabela 2). Para Rhizopus sp., verificou-se inibição do fungo após a aplicação dos extratos de mamona, melão-de-São-Caetano e mororó (Tabela 2).

No ensaio em que foram avaliados os efeitos dos extratos alcoólicos de goiaba, melão-de-São-
Caetano e mamona, aplicados na concentração de $100 \%$, verificou-se a incidência dos fungos: Aspergillus, Penicillium e Rhizopus; além destes, um morfotipo fúngico, com hifas não septadas de coloração branca, não identificado, também foi verificado. Para a percentagem de recobrimento fúngico houve inibições de $100,00 \%, 99,80 \%$ e $92,71 \%$, com o uso dos extratos de mamona, melão-de-São-Caetano e goiaba, respectivamente; e todos os fungos avaliados foram inibidos com o uso dos extratos (Tabela 3).

Tabela 3. Porcentagem de recobrimento micelial e incidência fúngica em sementes de amendoim BR1 após 0 tratamento ou não com extratos vegetais alcoólicas a $100 \%$.

\begin{tabular}{|c|c|c|c|c|c|}
\hline \multirow{3}{*}{$\mathrm{FV}^{1}$} & \multicolumn{4}{|c|}{ VARIÁVEIS } & \multirow[b]{3}{*}{$\mathrm{N}$. identif } \\
\hline & \multirow{2}{*}{$\begin{array}{c}\text { Percentagem de } \\
\text { Recobrimento Micelial }\end{array}$} & \multicolumn{3}{|c|}{ ESPÉCIES FUNGICAS } & \\
\hline & & Aspergillus spp. & Penicillium sp. & Rhizopus sp. & \\
\hline QM (TRATAMENTO) & $0,69^{\star *}$ & $041^{* *}$ & $0,002^{\star *}$ & $0,19^{* *}$ & 0,22 ** \\
\hline QM (RESÍDUO) & 0,04 & 0,01 & 0,002 & 0,03 & 0,001 \\
\hline CV $(\%)$ & 97,79 & 45,21 & 44,72 & 190,11 & 8,57 \\
\hline TRATAMENTOS $^{2}$ & \multicolumn{5}{|c|}{ MÉDIAS ${ }^{3}$} \\
\hline Testemunha & $0,77 \mathrm{a}$ & $0,57 \mathrm{a}$ & $0,04 \mathrm{a}$ & $0,39 a$ & $0,74 a$ \\
\hline Extrato de goiaba & $0,08 \mathrm{~b}$ & $0,00 \mathrm{~b}$ & $0,00 \mathrm{a}$ & $0,00 \mathrm{a}$ & $0,53 b$ \\
\hline Extrato de mamona & $0,00 \mathrm{~b}$ & $0,00 \mathrm{~b}$ & $0,00 \mathrm{a}$ & $0,00 a$ & $0,35 \mathrm{c}$ \\
\hline Extrato de melão-de-São-Caetano & $0,01 \mathrm{~b}$ & $0,00 \mathrm{~b}$ & $0,00 \mathrm{a}$ & $0,00 \mathrm{a}$ & $0,26 \mathrm{~d}$ \\
\hline DMS & 0,38 & 0,20 & 0,08 & 0,33 & 0,16 \\
\hline
\end{tabular}

${ }^{1}$ Teste $\mathrm{F}\left[{ }^{*}\right.$ Significativo a $1 \%$; ${ }^{*}$ Significativo a $5 \%$; ns: Não Significativo];

${ }^{2}$ As médias foram transformadas através da fórmula: arco sen $(\sqrt{ } \mathrm{x} / 100)$;

${ }^{3} \mathrm{~N}$. Identif. = fungo não identificado.

Para o terceiro ensaio, cujas sementes foram tratadas com os extratos aquosos na concentração de $100 \%$ de goiaba, mamona e melão-de-São-Caetano, houve predominância de: Aspergillus, Penicillium e Rhizopus, e de um morfotipo fúngico não identificado. Para a variável percentagem de recobrimento micelial houve inibição fúngica com a aplicação do extrato aquoso de goiaba. Aspergillus spp. foram inibidas após tratamento com o extrato de mamona. Penicillium sp. não foi inibido pelos extratos, tendo maior crescimento nos tratamentos com extratos aquosos de goiaba e melão-de-São-Caetano. Os extratos aquosos não tiveram efeito sobre Rhizopus sp. 0 fungo não identificado foi inibido por todas os extratos vegetais (Tabela 4).

Tabela 4. Porcentagem de recobrimento micelial e incidência fúngica em sementes de amendoim BR1 após 0 tratamento ou não com extratos vegetais aquosas a $100 \%$.

\begin{tabular}{|c|c|c|c|c|c|}
\hline \multirow{3}{*}{ FV 1} & \multicolumn{4}{|c|}{ VARIÁVEIS } & \multirow[b]{3}{*}{ N. identif. ${ }^{4}$} \\
\hline & Porcentagem de & \multicolumn{3}{|c|}{ ESPÉCIES FUNGICAS } & \\
\hline & Recobrimento Micelial & Aspergillus spp. & Penicillium sp. & Rhizopus sp. & \\
\hline QM (TRATAMENTO) & 0,10 ** & $0,14^{* *}$ & $0,15^{\text {** }}$ & $0,14^{* *}$ & $0,024^{* *}$ \\
\hline QM (RESÍDUO) & 0,00 & 0,002 & 0,007 & 0,002 & 0,0008 \\
\hline CV $(\%)$ & 1,89 & 5,42 & 22,45 & 190,11 & 48,58 \\
\hline TRATAMENTOS $^{2}$ & \multicolumn{5}{|c|}{ MÉDIAS $^{3}$} \\
\hline Testemunha & $1,15 b$ & $0,87 \mathrm{~b}$ & $0,25 \mathrm{~b}$ & $0,39 a$ & $0,13 a$ \\
\hline Extrato de goiaba & $0,91 \mathrm{c}$ & $0,94 \mathrm{~b}$ & $0,49 a$ & $0,00 \mathrm{a}$ & $0,00 \mathrm{~b}$ \\
\hline Extrato de mamona & $1,24 \mathrm{a}$ & $0,71 \mathrm{c}$ & $0,22 \mathrm{~b}$ & $0,00 \mathrm{a}$ & $0,00 \mathrm{~b}$ \\
\hline Extrato de melão-de-São-Caetano & $1,18 b$ & $1,12 \mathrm{a}$ & $0,57 \mathrm{a}$ & $0,00 \mathrm{a}$ & $0,00 \mathrm{~b}$ \\
\hline DMS & 0,03 & 0,08 & 0,15 & 0,33 & 0,03 \\
\hline
\end{tabular}

${ }^{1}$ Teste F [ ${ }^{*}$ Significativo a 1\%; **Significativo a 5\%; ns: Não Significativo];

${ }^{2}$ As médias foram transformadas através da fórmula: arco sen $(\sqrt{ } \mathrm{x} / 100)$;

${ }^{3} \mathrm{~N}$. Identif. = fungo não identificado. 
De acordo com Brasil (2009) os gêneros Aspergillus, Penicilliume Rhizopus degradam sementes de amendoim, sendo considerados patógenos póscolheita. Espécies de Cladosporium são relatadas como contaminantes de sementes de amendoim, não sendo considerado como patógenos para a cultura. Os trabalhos de Barroso (2009), Bruno et al. (2000) e Amorim et al. (2010) corroboram com os resultados encontrados no presente trabalho no que se refere aos fungos encontrados nas sementes de amendoim.

O controle de patógenos em sementes de amendoim também foi verificado por Cruz et al. (2009) que descreveram que os extratos de alfavaca [ Ocimum gratissimum, (Lamiaceae)], colônia [Alpinia speciosa, (Zingiberaceae)], caneleira [Cinnamomum zeylanicum, (Lauraceae)], cravo-da-índia [Syzygium aromaticum, (Myrtaceae)], hortelã-graúda (Plectranthus amboinicus, Lamiaceae) e tomilho [Thymus vulgaris, Lamiaceae) reduziram a incidência de Aspergillus sp. em grãos de amendoim; e que o extrato de hortelã-graúda, apresentou o maior controle. A eficácia da aplicação do extrato vegetal de melão-de-São-Caetano também foi verificada por Medeiros et al. (2012) no controle de $A$. niger em sementes de flamboyant-mirim [Caesalpinia pulcherrima, Fabaceae).

De acordo com os resultados do presente trabalho, verificou-se que os extratos vegetais obtidos utilizando-se a água como solvente foram menos efetivos do que os extratos alcoólicos (Tabelas 3 e 4). Resultados semelhantes foram encontrados por Lopes et al. (2011), com extratos alcoólico e aquoso de alho em sementes de angico [Anadenanthera colubrina
(Fabaceae)]; cujos autores verificaram que o extrato aquoso promoveu o crescimento de fungos do gênero Aspergillus e Rhizopus sp. nas sementes. Araujo et al. (2009) descreveram a diferença entre a ação de extratos alcoólicos e aquosos, os mesmos descrevem que 0 álcool pode dissolver melhor os compostos ativos presentes no material escolhido e/ou seu efeito também pode ser acentuado pela ação germicida natural do álcool. De acordo com os resultados obtidos no presente trabalho (Tabelas 3 e 4), o solvente álcool foi mais efetivo quanto à extração de compostos fungitóxicos de folhas de goiaba, mamona e melão-deSão-Caetano do que a água.

Quanto à fungitoxicidade dos extratos vegetais avaliados, verificou-se que todos os extratos vegetais inibiram o crescimento de $A$. flavus. Maiores inibições foram verificadas como os extratos de goiaba, seguidas pelos extratos de melão-de-São-Caetano, pinhãomanso, mororó, pitanga, mulungu, mamona, alho, eucalipto e carambola (Tabela 5). A. niger foi inibido por todos os extratos vegetais adicionadas ao meio de cultura, tendo inibição de $100 \%$ para os extratos de mamona e melão-de-São-Caetano (Tabela 5). Para 0 fungo Penicillium sp., verificou-se inibição total com os extratos de goiaba e pinhão-manso. 0 extrato de melão-de-São-Caetano inibiu o patógeno em 85,83\%, não diferindo dos extratos de goiaba e pinhão-manso. Inibições no crescimento micelial de Penicillium sp. também foram verificadas com a adição dos extratos de pitanga, mororó, eucalipto e mamona. Os extratos de mulungu, alho e carambola não diminuíram o crescimento do patógeno (Tabela 5).

Tabela 5. Crescimento micelial in vitro de A. flavus, A. niger e Penicillium spp. submetidos a diferentes extratos alcoólicos.

\begin{tabular}{lccc}
\hline \multicolumn{1}{c}{ TRATAMENTOS } & & ESPÉCIES FUNGICAS $^{1}$ & \\
\hline & Aspergillus flavus & Aspergillus niger & Penicillium sp. $^{-1,27 \mathrm{a}}$ \\
\hline Testemunha & $3,62 \mathrm{a}$ & $2,28 \mathrm{a}$ & $1,37 \mathrm{a}$ \\
Extrato de alho & $2,13 \mathrm{~b}$ & $0,57 \mathrm{~b}$ & $1,35 \mathrm{a}$ \\
Extrato de carambola & $2,35 \mathrm{~b}$ & $0,84 \mathrm{~b}$ & $0,95 \mathrm{~b}$ \\
Extrato de eucalipto & $2,23 \mathrm{~b}$ & $0,89 \mathrm{~b}$ & $0,00 \mathrm{c}$ \\
Extrato de goiaba & $0,12 \mathrm{c}$ & $0,13 \mathrm{~d}$ & $1,05 \mathrm{~b}$ \\
Extrato de mamona & $2,00 \mathrm{~b}$ & $0,00 \mathrm{~d}$ & $0,18 \mathrm{c}$ \\
Extrato de melão-de-São-Caetano & $0,69 \mathrm{c}$ & $0,0 \mathrm{~d}$ & $0,92 \mathrm{~b}$ \\
Extrato de mororó & $1,06 \mathrm{c}$ & $0,34 \mathrm{c}$ & $1,32 \mathrm{a}$ \\
Extrato de mulungu & $1,71 \mathrm{~b}$ & $0,77 \mathrm{~b}$ & $0,00 \mathrm{c}$ \\
Extrato de pinhão-manso & $0,73 \mathrm{c}$ & $0,08 \mathrm{~d}$ & $0,77 \mathrm{~b}$ \\
\hline \multicolumn{1}{c}{ Extrato de pitanga } & $1,56 \mathrm{~b}$ & $0,41 \mathrm{c}$ & 24,90 \\
\hline
\end{tabular}

${ }^{1}$ As letras diferentes nas colunas diferem entre si pelo Teste de Scott-Knott. ${ }^{2}$ Tratamentos com médias seguidas pela mesma letra não diferem entre si. 
Maior fungitoxicidade dos extratos vegetais alcoólicos foi verificada quando os fungos foram expostos os extratos diretamente no meio de cultura, na concentração de $20 \%$, do que quando os extratos foram aplicados nas sementes (Tabelas 2 e 5). Hipóteses para explicar as diferenças de efetividades são as seguintes: (i) processos bioquímicos envolvendo os extratos vegetais e as sementes podem ter reduzido à eficácia dos extratos vegetais quando aplicadas nas sementes; (ii) fungos são mais expostos aos extratos quando cultivados em meio de cultura acrescido com os extratos do que quando os extratos são aplicadas nas sementes, pois os patógenos estão protegidos pelo tecido vegetal, podendo muitas vezes não ter contato direto com 0 extrato.

Com isso, conclui-se que, os extratos vegetais alcoólicos de goiaba, mamona e melão-de-SãoCaetano possuem efeito fungitóxico, principalmente quando utilizados na concentração de $100 \%$ sobre as sementes de amendoim e os patógenos $A$. flavus, A. niger e Penicillium sp. associados as sementes de amendoim são sensíveis aos extratos alcoólicos de goiaba, melão-de-São-Caetano e mamona.

\section{REFERÊNCIAS BIBLIOGRÁFICAS}

AMORIM, E.P.R.; PREDES, R.C.T.; ELOY, A.P.; BEZERRA, I.C.; SOARES, L.P.R.; SILVA, J.C. Qualidade sanitária de grãos e frutos de amendoim comercializados no estado de Alagoas e identificação através de características culturais de espécies do gênero Aspergillus. Summa Phytopathologica, 2010, 36, 4, 309-312.

ARAUJO, R.C.Z:; CHALFOUN, S.M.; ANGÉLICO, C.L.; ARAUJO, J.B. PEREIRA, M.C. Avaliação in vitro da ação fungitóxiva de extratos de condimentos na inibição de fungos isolados de pães artesanais. Ciência Agrotécnica, 2009, 33, 2, 545-551.

BARROSO, M.L. Perdas quali-quantitativas na colheita mecanizada de sementes de amendoim (Arachis hypogaea L.). Dissertação de Mestrado. Pós graduação em Agronomia (Produção e Tecnologia de Sementes). Faculdade de Ciências Agrárias e Veterinárias UNESP, Câmpus de Jaboticabal, 2009. P.84.
BETTIOL, W. Métodos alternativos para o controle de doenças de plantas. In: Proteção de plantas na agricultura sustentável / Eds. Micherref, S.J.; Barros, R. - Recife: UFRPE, Imprensa Universitária, 2001. 368 p.

Brasil. Ministério da Agricultura, Pecuária e Abastecimento. Regras para análise de sementes / Ministério da Agricultura, Pecuária e Abastecimento. Secretaria de Defesa Agropecuária. - Brasília: Mapa/ ACS, 2009. $399 p$.

BRUNO, R.L.A.; AZEREDO, G.A.; QUEIROGA, V.P.; ARAÚJO, E.; DINIZ, E. Qualidade fisiológica e microflora de sementes de amendoim $c v$. BR1 durante 0 armazenamento. Revista Brasileira de Oleaginosas e Fibras, 2000, 4, 3, 141-152.

CELOTO, M.I.B.; PAPA, M. S.; SACRAMENTO, L.V. S.; CELOTO, F. J. Atividade antifúngica de extratos de Momordica charantia L. sobre Colletotrichum musae. Revista Brasileira de Plantas Medicinais, 2011, 13, 3, 337-341.

Conab. Companhia Nacional de Abastecimento. Acompanhamento de safra brasileira: grãos, décimo segundo levantamento, setembro 2014 / Companhia Nacional de Abastecimento. - Brasília: Conab, 2014. Disponível em: http://www.conab.gov.br/OlalaCMS/ uploads/arquivos/14_09_10_14_35_09_boletim_ graos_setembro_2014.pdf. Acesso em 21 de setembro de 2014.

CRUZ, M.E.S.; SCHWAN-ESTRADA, K.R.F.; RUPP, M.M.M.; FIORE, B.V. Controle Natural de Patógenos em Grãos de Amendoim e Café. Revista Brasileira de Agroecologia. 2009, 4, 2, 34-45.

DARONCO, M.V. Óleos essenciais no tratamento de sementes de soja (Glycine Max L.). Monografia (Graduação). Curso de Agronomia do Departamento de Estudos Agrários (DEAg) da Universidade Regional do Noroeste do Estado do Rio Grande do Sul (UNIJUÍ). Inuí, RS. 2013.

FONSECA, J.F.; BOTELHO, A.C.F. Atividade antifúngica do extrato de folhas de Psidium guajava do gênero Candida. Revista da Faculdade de Odontologia. 2010, 51, 1, 24-26. 
FREITAS, S. M.; MARTINS, S. S.; NOMI, A. K.; CAMPOS, A. F. Evolução do mercado brasileiro de amendoim: 1970-2000. O agronegócio do amendoim no Brasil. Campina Grande: Embrapa Algodão; Brasília: Embrapa InformaçãoTecnológica, p. 389419, 2005.

KIMATI, H.; AMORIM, L.; REZENDE, J.A.M.; BERGAMIN FILHO, A.; CAMARGO, L.E.A. ED. Manual de Fitopatologia. Volume 2. Doenças das Plantas Cultivadas. $4^{a}$ Edição. Editora Agronômica Ceres Ltda. São Paulo. 2005. 666p.

LOPES, I.S.; SANTOS, G.J.C.;ASSIS, M.M.;BEZERRA, M.R.; RANGEL J.A.F. Incidência fúngica com utilização de extrato de alho em sementes de Anadenanthera colubrina. Engenharia Ambiental, 2011, 8, 4, 31-38.

MEDEIROS, J.G.A.; SILVA, B.B.; ARAÚJO NETO, A.C.; NASCIMENTO, L.C. Fungos associados com sementes de flamboyant-mirim (Caesalpinia pulcherrima): incidência, efeito na germinação, transmissão e controle. Pesquisa Florística Brasileira, 2012, 32, 71, 303-308.

SANTOS, R.C.; MOREIRA, J.A.N.; VALLE, L.V.; FREIRE, R.M.M.; ALMEIDA, R.P. ARAÚJO, J. M.; SILVA, L.C. Amendoim BRS 151L7: Informações para seu cultivo/ Roseane Cavalcati dos Santos ... (et. al) Campina Grande, PB: Embrapa Algodão, 2010.
SILVA, F.A.S.E.; AZEVEDO, C.A.V. Principal Components Analysis in the Software AssistatStatistical Attendance. In: WORLD CONGRESS ON COMPUTERS IN: AGRICULTURE, 7, Reno-NVUSA: American Society of Agricultural and Biological Engineers, 2009.

SILVEIRA, P.S. Época de Semeadura e Densidade de Plantas em Cultivares de Amendoim no Recôncavo Sul Baiano. Dissertação de Mestrado. Pós Graduação em Ciências Agrárias. Universidade Federal do Recôncavo da Bahia, Cruz das Almas, BA, 2010. p. 122.

SUASSUNA, T.M.F.; COUTINHO, W.D.; SOFIATTI, W.; SUASSUNA, N.D.; GONDIM, T.M.S. Clima In: Cultivo do Amendoim. Sistemas de Produção, N.7. Embrapa Algodão, 2008.

VENTUROSO, L.R.; BACCHI, L.M.A.; GAVASSONI, W.L.; CONUS, L.A.; PONTIM, B.C.A. SOUZA, F.R. Inibição do crescimento in vitro de fitopatógenos sob diferentes concentrações de extratos de plantas medicinais. Arquivo do Instituto Biológico, 2012, 78, 1, 89-95. 